\title{
EFFECTS OF EARTHQUAKE ON FOUNDATIONS
}

\author{
Samridhi Singh', Faizan Ahmad², Bandita Paikaray ${ }^{3}$ \\ ${ }^{1,2}$ Student, School of Civil Engineering. KIIT University, Bhubaneswar, Odisha, India \\ (Email: sridzee@gmail.com,faizan6ahmad@gmail.com) \\ ${ }^{3}$ Senior Assistant Professor, School of Civil Engineering. KIIT University, Bhubaneswar, Odisha, India \\ (Email: banditace97@yahoo.com)
}

\begin{abstract}
As we know,shaking due to seismic waves causes damage to buildings. The damage maybe influenced by the characteristics of soil in the affected area.The objective of the paper is to show the effect of the earthquake on different types of foundations such as shallow, mat/raft, pile and structures like gravity dam, arch dam etc. The reaction of soil to the loading of the building when a building undergoes an earthquake disturbance as a behaviour of deflection is known as the soil structure interaction. The movement of ground during theearthquake induces kinematic and inertial loading which decreases the bearing capacity and increments the settlement of shallow foundations. In seismic regions, where kinematic interactions have been observed, the mat foundations experiences overturning moments. Pile foundations are influenced by both kinematic and inertial interactions which causes many failures. The convoluted oscillating arrangement of acceleration and ground motion in a gravity dam,developing ephemeral dynamic loads because of inertia of dam and confined water is the seismic activity generated in these dams. The arch dam foundations undergoes effects of inertia and flexibility due to the propagation of seismicwaves.
\end{abstract}

Keywords: earthquake effect, soil structure interaction, shallow, mat, pilefoundation, gravity dam, arch dam.

\section{INTRODUCTION}

A member of a structure, that connects it to the ground and distribute loads tothe ground is Foundation. There are different types of foundation for different purposes. Modern types of foundation are Shallow foundation and Deep foundation. Force distribution on foundation are shown in Figure 1.a. ${ }^{[1]}$ Foundations are constructed to bear sufficient load capacity depending on the type of subsoil aiding the foundation. The settling of the foundation below thelevel of initial construction to a point where damage has already been happened is known as foundation failure. The extent of damage ensuing from earthquakes in the earthquake affected areais stimulated by the behaviour of the soil. Here the damage is linked to the overall vulnerability of the soil which leads to enormous permanent movements of the lower surface. Thus, for an example, deposition of granular soils is compressed by the vibrations caused by the earthquake that develops massive and differential settlements in the lower surface. During earthquake, the soil consisting of loose granular materials, leads to inclination and settlement of structures. The examples of damage as a result of this cause are depicted in Figures 1.b and1. c, Figure $1 . b^{[2]}$ illustrates an island in Chile, that was partly flooded as a consequence of dual effect of ground settlement and tectonic plate displacement because of compaction during the earthquake in 1960. Figure 1.cshows transmitted settling of backfill of a bridge in the 1964 Nigatan earthquake. ${ }^{1}$ The soil-structure interaction (SSI) influences the structures' seismic response. Collapse of buildings resting on piles in damp soils are noticed after most earthquakes, like the survey after 1995 Kobe earthquake (Figure 1.d), Niigata earthquake in 1964 and the 2001 Bhuj earthquake ${ }^{2}$ (Figure 1.e). In this paper, the application to the ground motion for site specific SSI analysis is presented. In several earthquake-prone regions shallow foundations are used for small size structures. The bearing capability of a shallow foundation is decreased when the horizontal loads and rocking moments acts on the foundation $^{[3]}$. The reaction of pile during seismic loading includes the evaluation of kinematic curving that occurs due to the sideward displacement of a pile along with the mechanical phenomenon forces acting on the cap mass, that imitates the structure. This paper analyses the reaction of concrete gravity dam to earthquake surface motion and the outcome of dam-water interaction, rock-dam-foundation interaction and reservoir- bottom absorption. The reason for cracking in aconcrete dam could also be several folds: seismic actions, thermal disparities because of exterior or interior sources, unequal settlements of the foundation, hardening of the concrete, chemical reactions during the settling, etc.. In thispaper, the seismic response of arch and gravity dams and its effect on foundationis studied. Arch dams, created for several crucial functions, serve humans through control, electricity power, navigation, and provision of drinking water, irrigation, and industrial wants. Consequently, these structures need subtle

engineering for designing and constructing to avoid risks from of a dams' failure and ensuing damage. Despite the very fact that dam failures are very rare,variety of things together with age, construction deficiencies, inadequate maintenance and weather or seismic events contribute to the chance of a dams' failure. This paper discusses about the impact of earthquake on different types of foundation. 


\subsection{FOUNDATION TYPES}

\subsubsection{Historic foundation types}

These foundations can be classified as Pad stones, Stone Foundations, Earth fast or Post in Ground Constructions, Rubble Trench foundations.

\subsubsection{Modern foundation types}

Nowadays, these foundation types are generally used for constructionpurposes. These can be classified as Shallow Foundations and Deep foundations.

The objectives and purposes of a foundation are as follows:A foundation is a structure constructed below the ground level to support theload of the weight of the structure above it. It gives lateral stability to thestructure by providing a rigid and even surface for transferring the load. The foundation rests on a solid ground, foundation bed. [1] [2] The purposes of the foundation is first, to make the load of the structure withinthe safe bearing capacity by disbursing the load over a large bearing area. Also, preventing lateral movement of the supporting material, increasing stability ofthe structure as a whole, and securing firm bed for building operations.[3]

\subsection{FAILURE OF FOUNDATION}

Failure in foundations can be due to various reasons such asLateral movementof soil adjacent to the structure, Unequal settlement of sub-soil, Overturning of the structure due to lateral pressure, Unequal settlement of the masonry,contraction due to removal of moisture from the soil beneath the foundation, Action of atmosphere, Lateral escape of the soil below the foundation etc.

The effects of foundation failures can range from bulging floors to cracked walls to displaced mouldings. The external signs are wall rotation, cracked and/orbroken foundation, separation around garage door, windows and/or walls,cracked bricks. While the internal hints are cracks on floors , disordered doorsand windows, broken sheetrock. The ground deformations which are permanent completely break the structure. Some foundation types can resistthese permanent ground deformity. Most damage in a building is a result ofground movement. The building's foundations vibrate in the same way as the surrounding ground when the ground shakes at the building site. The building reaction to an earthquake movement occurs over a few seconds. During this time, many kinds of seismic waves combine to vibrate the building in ways that are distinct in detail. Additionally, as a outcomeof variousgeological nature of every site, deviations in fault seepage, different rocks in which the waves travel, overall shaking at every site is different. The aspect of every buildings are varied in method of analysis configuration ,dimension, age, architectural system, or quality of construction. The above aspects affects the reaction of the building. Instead of the complex nature of the interactions among the building and ground within the few seconds of movement there is wide understanding of how differently building types can perform under the different conditions. During earthquakes, when external forces act on the system, neither the structural displacements nor ground displacements are independent of eachother.

\subsection{The Soil Structure Interaction}

It is conventionally considered to be beneficial for the seismic response of a structure. The soft soil debris could remarkably extend the occurrence of seismic waves and that increment in natural period of architecture might result to resonance with extended surface vibration period. The perpetual deformity anddegradation of soil may further exasperate architectural seismic reaction. When Earthquake excitation happens in a structure, it connects with the foundation and the soil and thus leads to a change in the movement of the ground surface. Soil-Structure Interaction generally can be distinguished into two phenomena: inertial and kinematic interaction. The ground movement due to Earthquakeresults in soil rearrangement which is called as free-field motion. Nevertheless, the foundation fixed into the soil does not ensue the free surface motion. This inefficiency of the foundation in matching the free surface motion causes the kinematic interaction. Contrarily, Inertial interaction is defined as the mass of the superstructure which imparts the mechanical force to the soil leading to the further deformity in the soil.[4]Kinematic effect being more dominant at low level of ground shaking results inthe extension of period and increment in the emission damping. Nevertheless, inertial interaction becomes predominant with the commencement of stronger vibration, soil modulus deterioration and soilpile gaping limit radiationdamping causing bending strains and enormous movement fixed near the groundlevel which results in pile damage earthquake effects on deep and shallow foundations are accounted for bydesigning them structurally to ensure serviceability and provide necessary strength. Strength considerations primarily involves ensuring that the loads on foundation remain well below the allowable bearing capacity specified underseismic conditions and the serviceability of foundation is ensured by designing the substructure as per the estimated permanent ground deformation. [5] The responses of structures during an earthquake are usually analysed assuming that the foundations are rigidly fixed at their base. Such analysation generally anticipates overturning moment at the base that transcends the maximum allowable overturning resistance because gravity force, meaning that a part ofmat foundation would occasionally exhilarate during an earthquake.The nonlinear behaviour of shallow foundations during excessive amplitude earthquake-induced loading can disperse the seismic energy by the soil yielding mechanism underneath the foundation. The upliftment along with the yielding causes extreme fugitive and enduring deformities such as sliding, rocking andsettlement [6].

Structures that are sufficiently designed opposing the dynamic loads amid anearthquake will have momentous prospect of seismic failure because of enormous perpetual ground movements due to surface fault wreckage.Subsidiary fractures also adds significantly to the comprehensive devastationdue to enormous ground movements, and these are placed at comparatively large distances from the position of the central element of the fault fracture. 


\subsection{SHALLOW FOUNDATION- MAT}

The earthquake responses of architecture are generally evaluated assuming that the is foundation is rigidly fixed to the ground soil. This evaluation predicts abase overturning moment exceeding the allowable overturning resistancebecause of gravity force, signifies that mat foundation experiences upliftment during the earthquake.[7] A fortified concrete mat foundation is a general kind of foundation provided invarious structures. They are a kind of shallow foundation that implements bearing capacity of the soil at the building's foundationfor transferring the loadsto the soil. In comparison to the individual spread footings, a mat foundation encloses all or portion of the footprint of a building. A reinforced concrete matis much wider and experiences more considerable loads from the building as compared to an ordinary slab.[8]

It is generally beneficial where load criteria and soil causes considerable settlement in each and every spread footing but else a deep foundation system is favourable. A mat foundation is generally used to disburse the bearing pressureon a large footprint/ or to prevent uplift forces which can develop in cases of buildings with compelling overturning moments. Other usual operation for a mat foundation is where spread footings are huge and in proximity.Effective soil structure complications have been studied by considering the foundation fixed to the soil. Although it has been studied that during strong earthquake, many architectural systems have been subjected to foundation exhilaration, solid bodies or clusters of solid bodies provides outstanding examples of overturning structures. Most of the engineering architectures areductile and often display foundation upliftment. Apart from very rigid bodies, the uplift is reduced by the structural deformities and forces as observed by Chopra and Yim[9].The reverberation of shallow foundations under sidewise periodic loading iscommonly nonlinear and consists ofsettlement, sliding, rocking, and also includessoil yielding and foundation exhilaration. The dispersion of seismicenergy using the procedure of soil yielding underneath the foundation is mainly because of the nonlinear behaviour of shallow foundations during highamplitude earthquake-induced loading.

\subsection{PILE FOUNDATION}

In most of the seismic design codes, pile foundations are designed solely againsthe inertial force. Nonetheless, curvature of piles are generated and subsequently a bending moment along their whole length is caused by the seismic waves.

Analyzing pilefoundations for seismic loading considers the inertial load that develops from pile and soil synergy, also considering the interpretation of kinematic interactions which develops from the shaking of the surrounding soiland the pile. Corresponding soil-pile interaction also accounts the rigidness deterioration that develops due to seismic loading. Outcome of a ground response analysis collected from different studies were utilized for the analysisof soilpile interaction .Pile foundation structure built on a soft ground receivesboth influences of the Inertial Interaction and the Kinematic interaction. As aresult, these two interactions during earthquakes induces pile forces. Many of failures in pile foundation arose from the large inertia forces transmitted on to the foundation. The reckoning of kinematic curving that develops due to the sideward movements and displacements that are established on the pile due to ground movement and the inertial forces acts on the cap mass[10]. Due to the effects of earth pressures on the foundation and pile integrated in, pseudo staticanalysis is carried out to evaluate the maximum moment distribution in pile. Generally, we can say that the arithmetic sum of the two stresses due to the inertial and kinematic effects is equivalent to the maximum moment. During earthquake, segregation and movement between soil and the pile have acompelling reaction on the complicated behaviour of pile groups. Simultaneously, segregation of pile and soil, the behaviour of soil medium neighbouring the piles varies during strong seismic loading. Pile foundations experiences two unique effects under dynamic seismic loading. Firstly,behaviour of the soil enclosing the piles is varying. Second, amplified inertial forces are developed in the soil over the pile heads, which causes segregation between the pile and soil. Geometrical non linearity is the non linearity as a result of the segregation between the soil-pile, which have momentous impacton the compelling behaviour of pile foundations. The earthquake response of pile foundations is quite a complicated process which involves inertial interaction between pile foundation and structure, kinematic interaction amidst soil and pile, induced seismicity of porewater pressures (PWP) and the varying reaction of soils to dynamic seismic vibrations.[11]

The foundation Input Motion is simply that of free field, which performs theinertial interaction analysis of a architecture based on piles, thereby ignoring the kinematic interaction amidst piles and soil developed by the movement of seismic waves.[12].The reaction of a structure to an earthquake is generally anticipated presuming that the support motion at the foundation level is only that of the free-field. However, the upper structure collaborates with its foundation and the soil surrounding it, generating extra soil deformities, which sums up to those developed from the movement of seismic waves, so as the movement in the proximity of the foundation can be different extensively from that of the free-field.

\subsection{GRAVITY DAMS}

Concrete gravity dams are designed with comfort on dam site, where a indigenous foundation strong enough to hold the excessive weight of the damexists. A concrete gravity dam is a inundated complex structure that is constructed in way that its own weight defies the extrinsic forces, henceforth its behaviour under tectonic movements due to earthquakes has gained tremendous attention of the researchers. These structures are effective, most durable andsolid, and so demand very low maintenance.[13]Such dam failure might result indisastrousevents with rapid discharge of reservoir and destruction ofneighbouring biodiversity. For example, The Fujinuma Dam in Sukagawa City, Fukushima Prefecture, Japan, collapsed 20 to 25 minutes later the Tōhoku earthquake as the entire reservoir 
overtopped/ overflowed the dam's crest asshown in Figure 1.6 .a..The Figure 1.6.b depicts some of the causes whichresulted in the overflow of the stored water which lead to catastrophic event.[14]. Therefore, in recent years the safety of dam has become major concernin different areas of the world .The collapse of dams in earthquake prone zonesis prevented by determining the behaviour of the dam at any age during its existence, in order to implement alleviate measures enhance the strength ofthe dam at the correctmoment. Therefore, for designing and safe analysation ofan earthquake defiant dam, it is very essential to apply a rational dynamicanalysis procedure. In this paper, the response of concrete gravity dams on seismic movements due to earthquake is evaluated by acknowledging the effects of reservoir dam interaction. The concrete gravity dams gains zones of internal or micro cracking during its operation. The cracking in concrete dams originate within the passage of time, operation or construction. The cracking maybebecause of the irregular settlements, internal chemical reactions throughout thesettlement procedure and thermal variations due to internal or external sourcesetc. The fracture in dam is usually of a lot of importance and it causes ruinous consequences like loss of lives and damage the material possessions if the dam collapses. These dams are constructed in regions of seismically active areas to prevent two different levels of earthquake or seismic actions. For these gravity dams which are constructed in step with the present criterion, the passive and seismic compressing load are typically abundant. Also, the concrete gravity dams depicts that the seismic ground surface movement will manufacture tensile load which out passes the durability of the concrete mass while analysing the linear dynamics of the dams. In these situations, a continuous analysis isn't anymore valid as a result of tensile cracks can travel and proliferates within the concrete, therefore moving the vibrational characteristics and effective reaction of the concrete gravity dam. The water may completely fill within the fractures on the upstream face of the dam and hence, the pressure is generated in the influenced crack because of the behaviour of the gravity dam. Similarly,expansive cracking is an important development to contemplate within unstablereaction of these dams. The impact of pressures within cracks due to impounded water is lesser than those of cracks which solely depends on the worldwide modal properties. In this review paper, the unstable rupture reaction of the concrete gravity dams is studied by consideration of the outcome of dam reservoir interaction[15].

The rupture situations in the gravity dam at six different times are illustrated inFigure $1.6 \mathrm{c}$ and Figure $1.6 \mathrm{~d}$. The rupture or cracking situations within the dam at six particular times is shown in upstream face of the dam. The nature of a bare crack in an exceedingly definite component is shown by colouring or shading the whole component space. The incomplete crack situations are depicted by small dots in the elementary sentence. Those fundamental items that have been never softened are not markedin the shown figure. Owing to the eternal fixibility of the foundation, a fracture propagation of the bottom of the dam is induced by the force acting per unit area
concentration.Initially thedownstream face of the dam consists of the cracks in the horizontal region propagating far inside the dam and the band of crack occurs which slides downdue to the compressive forces developed from the rocking of the top of the dam. The initially generated cracks in the heel of the dam moves from the heel to thetoe. The crack bands consisting of soft and cracked elements can be opened and closed at different times. The overall stability of the dam is retained as a result of upstream and downstream faces which are not under tensile stresses at the identical time[15].

\subsection{ARCH DAMS}

The compelling analysis of arch dams is exclusively complicated because they should be treated as threedimensional systems which perceives the semi-unconfined dimension of the reservoir and the domain of the foundation rock. The effective analysis of arch dams should be considering the various factors such as, interaction of damfoundation rock, wave absorption at the reservoirborder line, dam-water interaction, water compressibility, interaction of dam-foundation rock, and structural diversities in the ground surface movement over the canyon. Moreover, during intensive earthquake motions, vertical construction joints may get slipped or opened up, and the concrete may crack;thus, nonlinear dynamic analyses may be necessary.[16]The Kariba DamFigure 1.7 a in the Kariba Gorge of

the Zambezi river basinbetween Zambia and Zimbabwe, has become a major threat to millions in thatarea. The major concern of the dam is the geological heterogenity of the south bank abutment and the behaviour of concrete under wetted conditions. Another potential threat to the complex is the unstable weathered material sitting on clayseams downstream of the wall.[17]It is predicted to fail within three years Figure1.7 b.Until and unless it is repaired. If the dam fails, huge flood of water wouldsplit a big gorgetowards the length of the Zambezi River on its way to the Indian Ocean. The factors considerably influencing the 3-D analysis of arch dams area unit analyzed: the semi limitless dimension of the reservoir and therefore the domains of rock foundations, wave retention at the reservoir boundary line,dam-water interaction, softness of water, dam-foundation rock interaction, and structural diversities within the ground surface motion at the interface of damand rock. The analysis of high arch dam safety largely considers two kind ofanalysis, that is that the results of completely different criterion for planning andobject safety. the primary one is expounded to optimum planning (optimumearthquakeresistant design) that, as stability criterion, aren't allowed cracks occurrences. The retention of water at the reservoir border has less impact onthe reaction of the dam to cross stream ground motion than on the upstream ground motion. The small increment in the stresses associated with the arch dam is in distinction to the concrete gravity dam because of its interaction reduction.[18] 


\subsection{CONCLUSION}

The effect of earthquake on the foundation of different architectural structures are influenced in a number of ways by the nature and the behaviour of the soils in the affected area. In spite of modern Engineering technology, the complete structure may collapse in an earthquake if the foundation of the structure lies on soft soil. However the geotechnical engineers can incredibly enhance the structure how the structure and foundation together react to the seismic waves.

The solutions to prevent the damage are :-

1)The super structure is tied to the foundation so that the entire structure acts as a single unit.

2)The building can be floated above its foundation which is known as base isolation .

Resulting to which, lateral acceleration is decreased and the structure experiences far less deformity and damage. However, the structure still canreceive fixed amount of vibrational energy during seismic loading even withbase isolation system in place. The building itself can drench this energy tosome level, however its capability to do so is proportionate with the ductile nature of the material used during construction.

Presently, materials such as combination of rubber and steel plates are invented which are used on buildings to absorb the vibration due to the Earthquake. These are few ways by which we could prevent some losses during earthquakes infuture. Earthquakes cannot be stopped, but we can learn more, in aspiration of discovering new ways to protect ourselves from their dangerous effects. Simple precautions are most effective ways to minimise Earthquake damage.

\section{REFERENCES}

[1] Tokimatsu, K., Suzuki, H., Sato M.," Effects of inertial and kinematic interaction on seismic behaviour of pile with embedded foundation " Nishikameya 1501-21, Shijimi, MIki-shi, Hyogo-ken 673-0515, Japan, November2004.

[2] Seed, B.H., Chane,C.R ., Pamukcu ,S.,"Earthquake effects on Soil-Foundation Systems", Springer US., 1991.

[3] Dash, R. S., Govindaraju, L., Bhattacharya, S., "Case study of damages of the Kandla Port and Customs Office tower supported on a mat-pile foundation in liquefied soils under the 2001 Bhuj earthquake", Elsevier Ltd. ,DLF Cyber City, Phase II ,Gurgaon, India, 1980.

[4] Roy, D.," Design Of Shallow And Deep Foundations For Earthquakes", Geotechnical Earthquake Engineering Design of Shallow and Deep Foundations for Earthquakes., IIT Gandhinagar - March , 2013

[5] Lou,M.,Wang, H .,Chen, X.,Zhai, Y., "Structure-soil structure interaction: Literature review", Elsevier Ltd., Amsterdam, August2011

[6] Trombetta, W.N.,Mason, B., Hutchinson,C.T., Zupan,D.,Bray,D.J .,Kutter, L.B., " Nonlinear Soil Foundation-Structure and Structure-Soil-Structure Interaction: Engineering Demands",J. Struct. Eng., 2014
[7] Menglin, L.,Wang, H.,Chen, X .,Zhai, Y.," Structuresoil structure interaction: Literature review", Volume 31,Issue 12, December 2011, Pages 1724-1731.

[8] Knappett, J.A., Haigh, S.K., Madabhushi, S.P.G ," Mechanisms of failure for shallow foundations under earthquake loading" , Schofield Centre, University of Cambridge, Madingley Road, Cambridge CB3 OEL, UK,2004.

[9] Asgari, A.,Golshani, A.,Bagheri, M., "Numerical evaluation of seismic response of shallow foundation on loose silt and silty sand ",Journal Of Earth System Science, Mar 2014, p.p. 365-379.

[10] Klemencic, R.,McFarlane, S.I ., Hawkins, M.N ., Nikolaou, S., "Seismic Design of Reinforced Concrete Mat Foundations A Guide for Practicing Engineers", Pacific Earthquake Engineering Research (PEER) Center, NIST GCR 12-917-22, 2012.

[11] Kim, K.D., Lee, H.S., Kim, S.D., Choo, W.Y., Park, G.H," Rocking Effect of a Mat Foundation on the Earthquake Response of Structures" , American Society of Civil Engineers, September 2014.

[12] Faramarz, K., Mehdi, S., Farzane, P., "p-delta effects on earthquake response of structures with foundation uplift" , Elsevier, Volume 34, Page 25-36, March 2012.

[13] Murono, Y., Nishimura, A, "Evaluation Of Seismic Force Of Pile Foundation Induced By Inertial And Kinematic Interaction"

[14] Phanikanth, V.S., Choudhury, D ., Reddy, G.R, "Behavior of Single Pile in Liquefied Deposits during Earthquakes",10.1061/(ASCE)GM.1943-5622.

[15] Tokimatsua, K., Suzukia, H., Satob, M, "Effects of inertial and kinematic interaction on seismic behavior of pile with embedded foundation",Haigh SK ,University Of Cambridge(United Kingdom),ProQuest Dissertations Publishing,2002.

[16]Das, K., Das, K.P ., Halder,L., " Seismic Response of Concrete Gravity Dam",HTC2011

[17] Harder, F.L., Kelson, I.K., Kishida, Tadahiro., Kayen R., " Preliminary Observations of the Fujinuma Dam Failure Following the March 11, 2011 Tohoku Offshore Earthquake, Japan", Geotechnical Extreme Events Reconnaissance (GEER),June2011

[18] Calayir, Y., Karaton, M., "Seismic fracture analysis of concrete gravity dams including dam-reservoir interaction" , Department of Civil Engineering, Faculty of Engineering, Firat University, 23279 Elazig, Turkey,2016.

[19]Fenves, G., Chopra, K. A.,(1987) " Simplified Earthquake Analysis Of Concrete Gravity Dams: Combined Hydrodynamic and Foundation Interaction Effects". J. Struct. Eng., 113(8), 1688-1708 American Society of Civil Engineers, August 1987.

[20] Magadza, H.D.C," Kariba reservoir - Experience and lessons learned ", Lakes \& Reservoirs: Research \& Management, 11:271-286. December 2006.

[21] Chopra, K.A. ,"Earthquake Analysis Of Arch Dams: Factors to be considered", 14thWorld Conference On Earthquake Engineering, Beijing, China" October 1217,2008 
[22] Gao, L., Jianguo,D ., Zhiqiang, H., " Earthquake analysis of arch and gravity dams including the effects of foundation inhomogeneity", Front. Archit. Civ. Eng. China 2007.

\section{FIGURES}

1. Figure 1.a

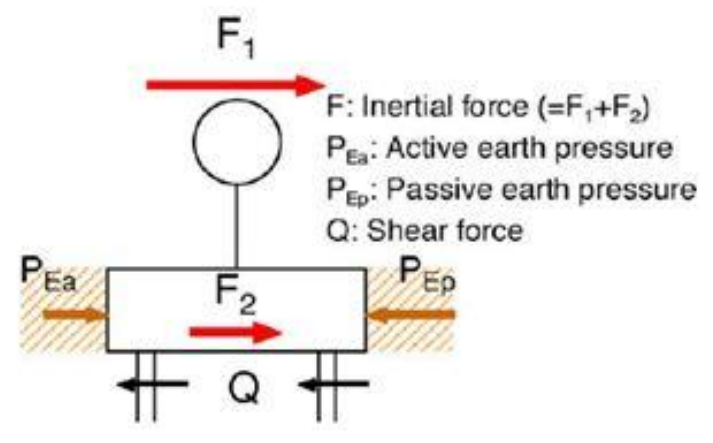

2. Figure 1.b

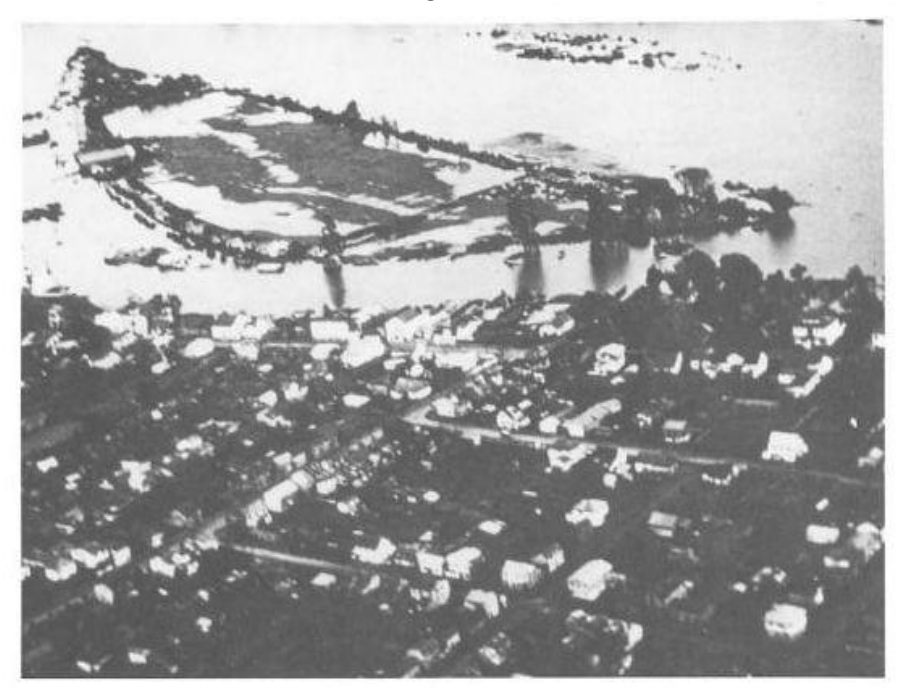

3. Figure 1.c

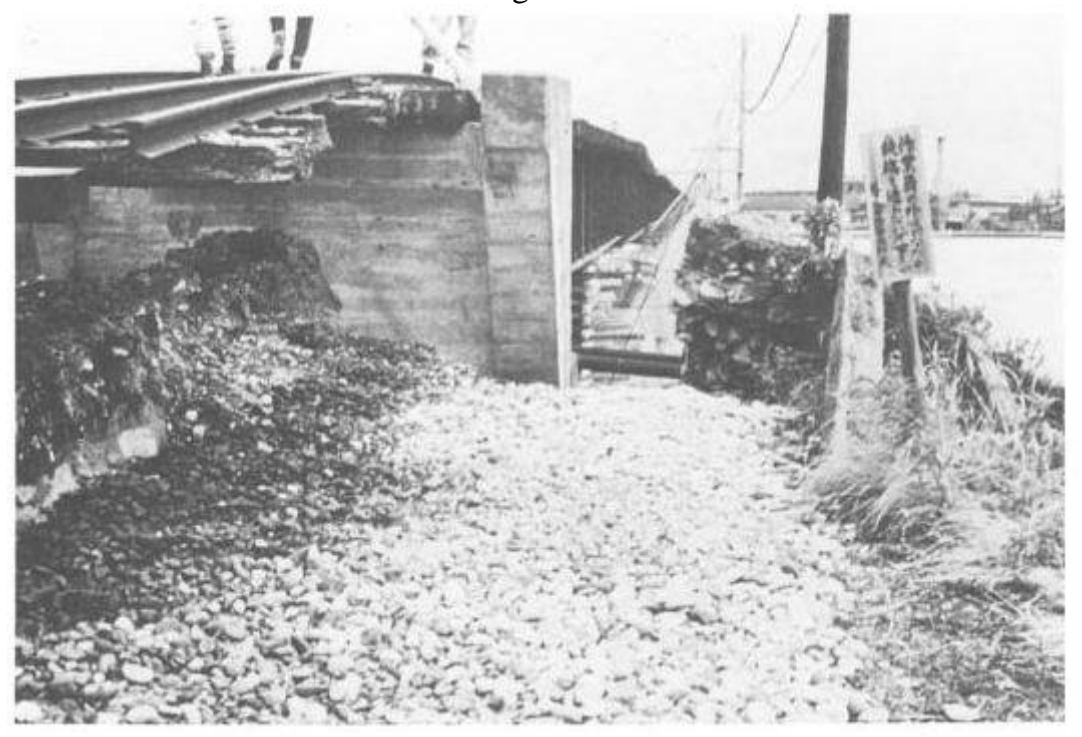


4. Figure 1.d

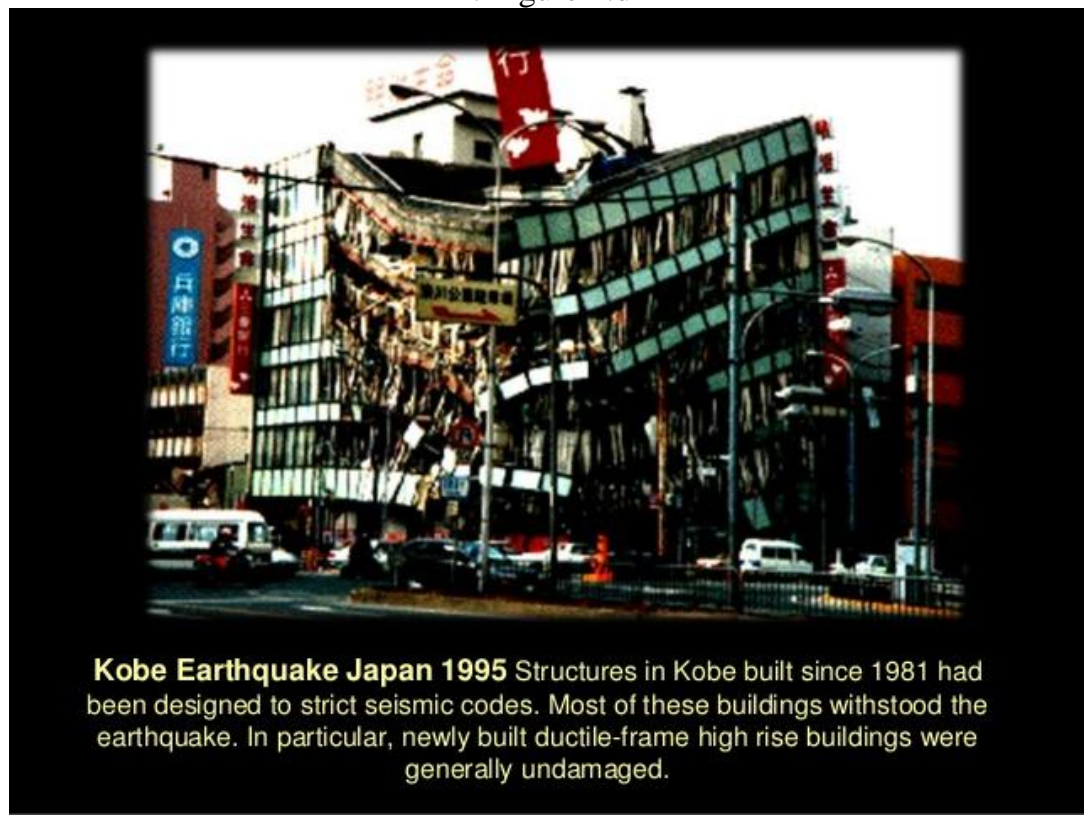

5. Figure 1.e

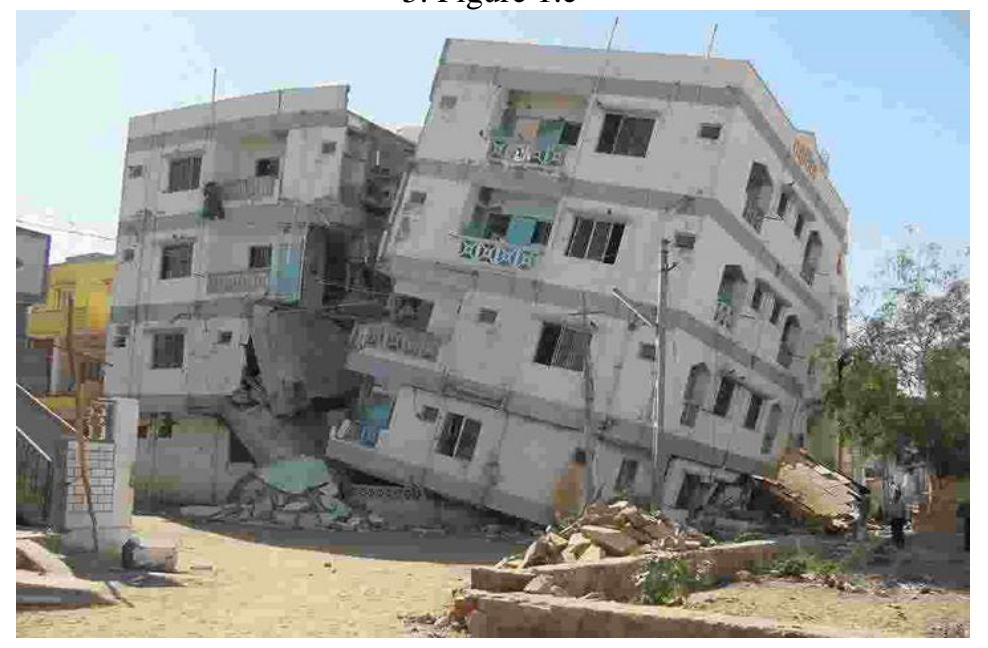

7. Figure 1.5.a

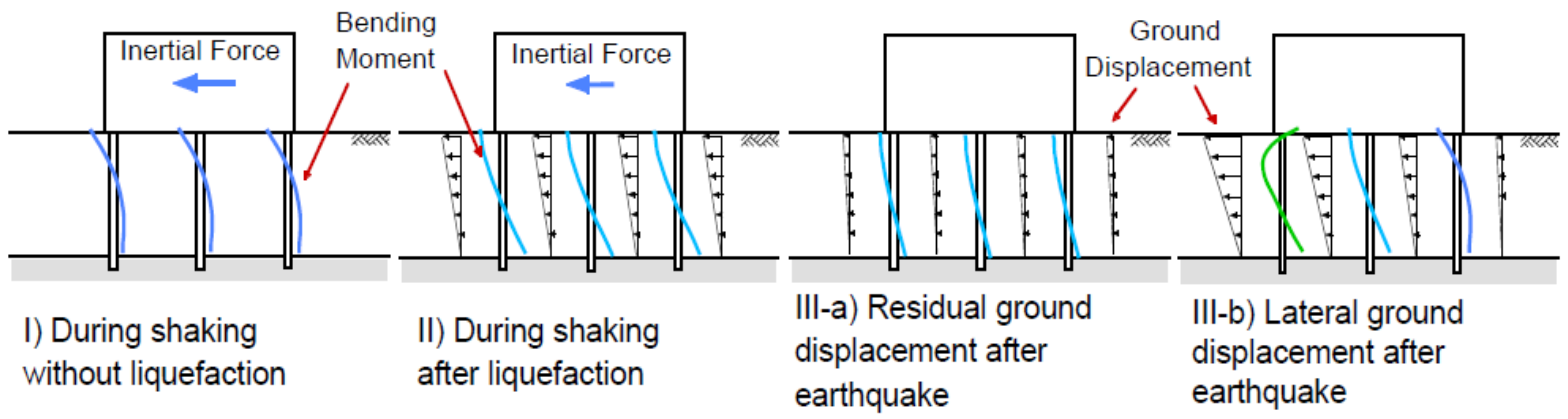

Fig. 1. Effects of inertial and kinematic forces on piles.| 


\section{Figure 1.6.a}

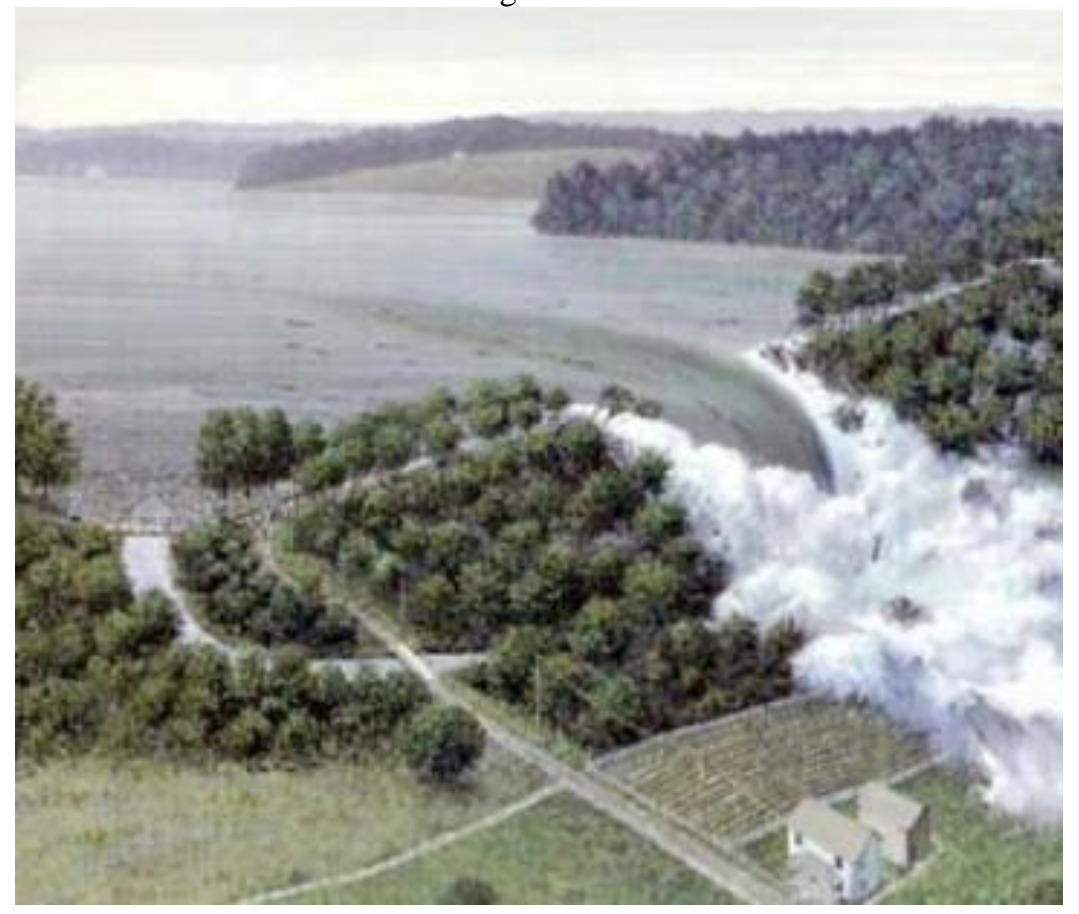

9. Figure 1.6.b

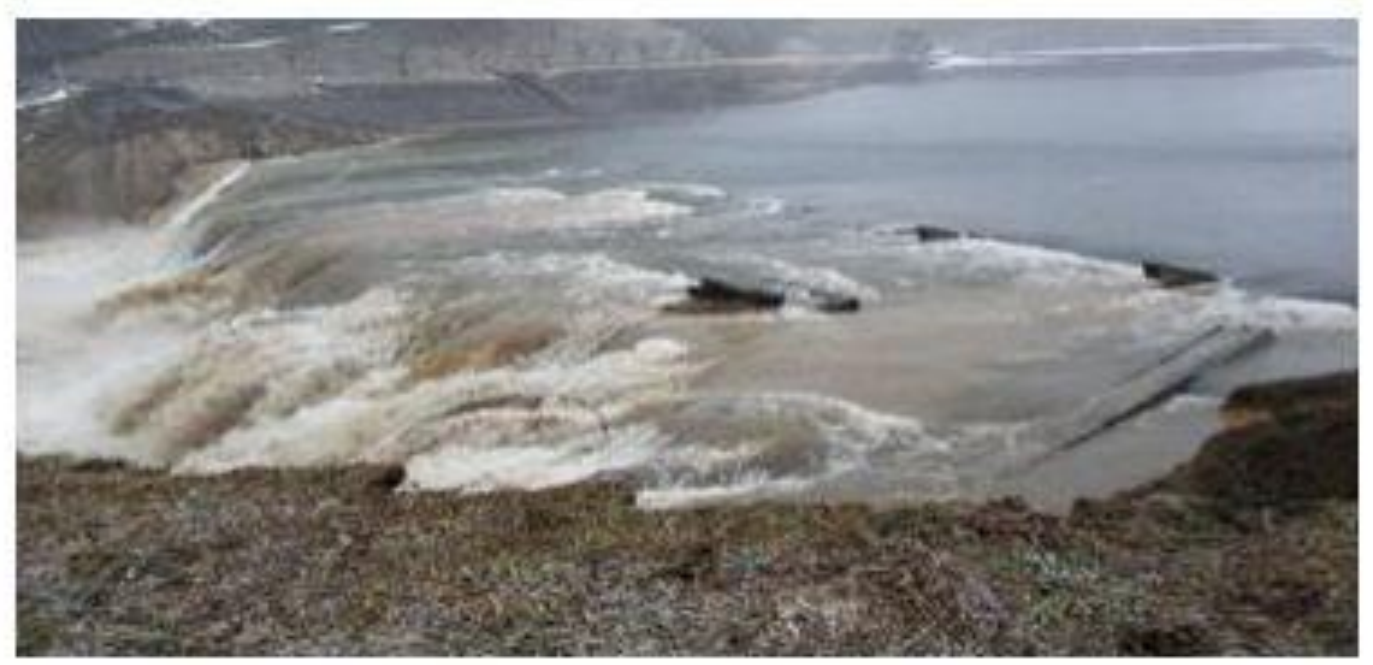

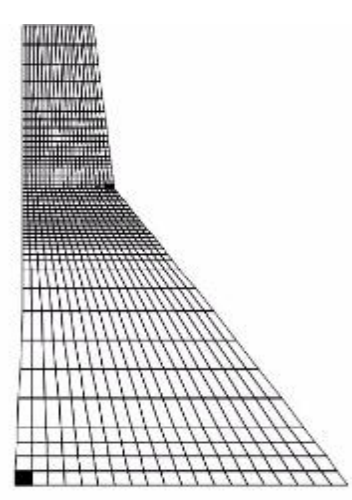

(a)

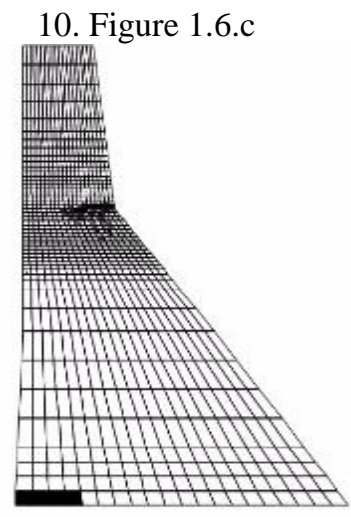

(b)

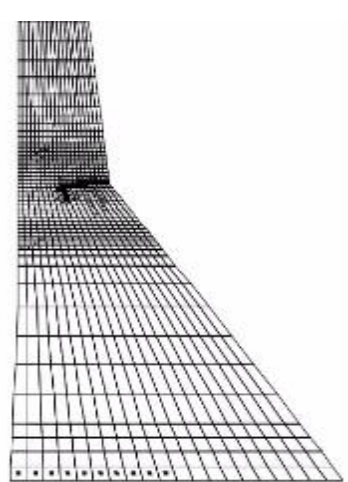

(c) 


\section{Figure 1.6.d}

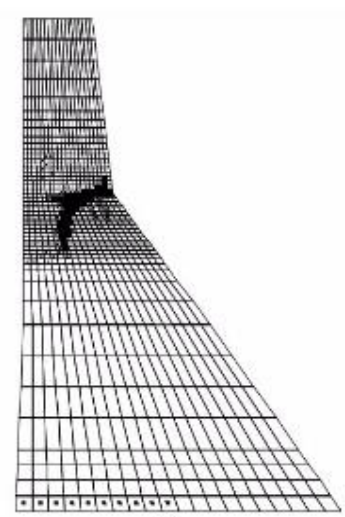

(d)

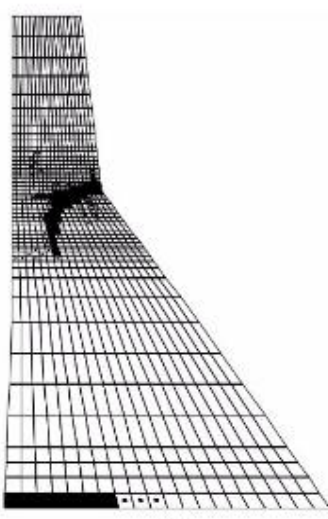

(e)

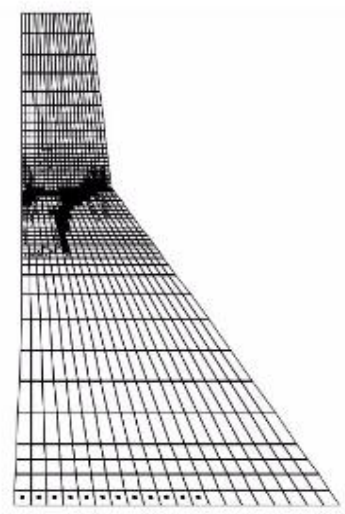

(f)

Cracking cases in the dam at six selected times. (a) $t=2.156 \mathrm{~s} ;(\mathrm{b}) \mathrm{t}=2.846 \mathrm{~s} ;$ (c) $\mathrm{t}=3.698 \mathrm{~s} ;(\mathrm{d}) \mathrm{t}=4.092 \mathrm{~s} ;(\mathrm{e}) \mathrm{t}$ $=4.142 \mathrm{~s}$; and $(\mathrm{f}) \mathrm{t}=4.536 \mathrm{~s}$.

12. Figure 1.7.a

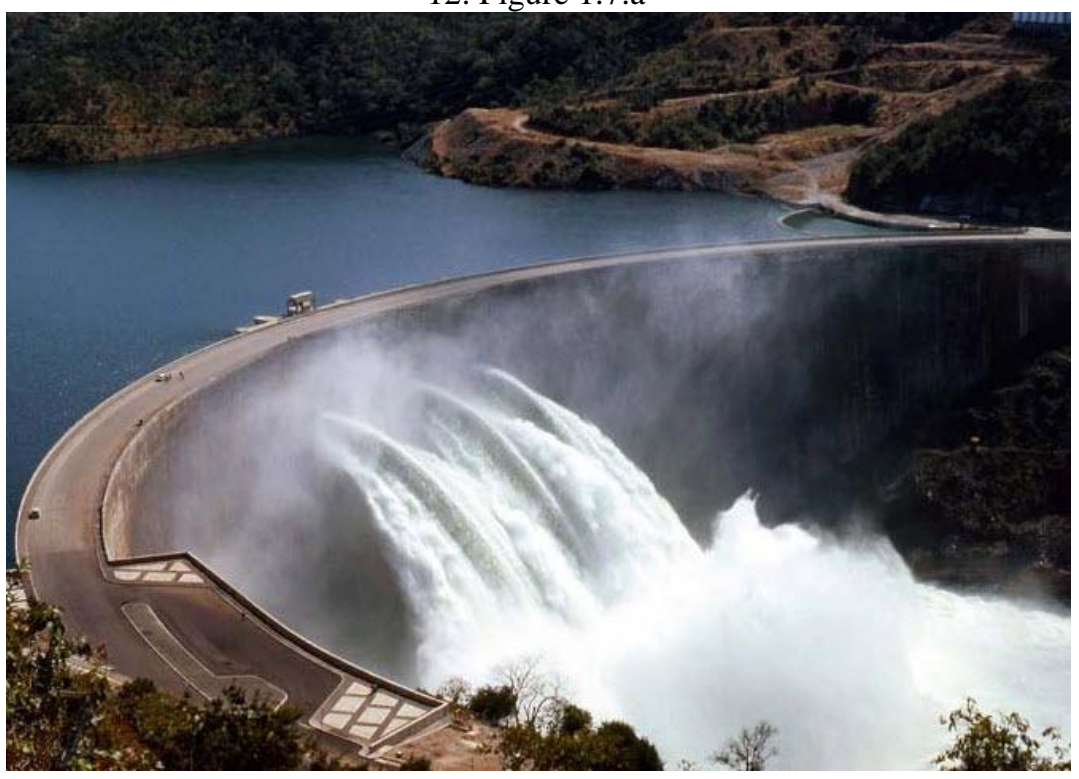

13. Figure 1.7.b

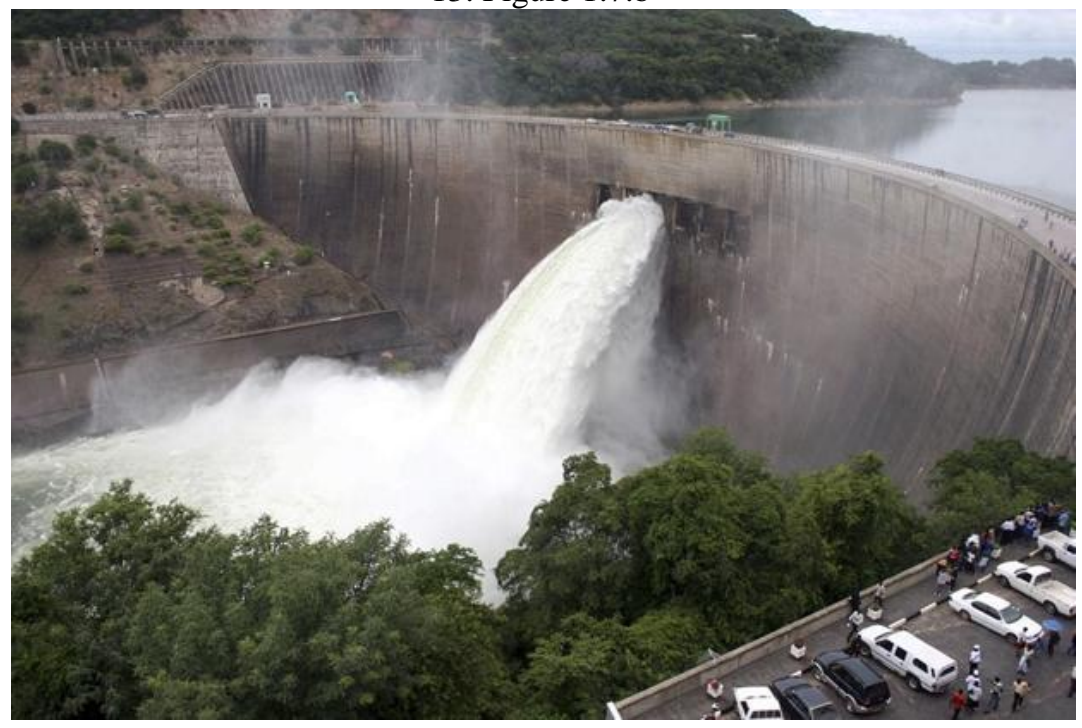

